\title{
Increased augmentation index in patients with Ehlers-Danlos syndrome
}

\author{
Maurice Roeder ${ }^{1} \mathbb{D}$, Sira Thiel ${ }^{1}$, Frederic Baumann ${ }^{2}$, Noriane A. Sievi ${ }^{1}$, Marianne Rohrbach ${ }^{3}$, Malcolm Kohler $^{1,4^{*}+}$ and \\ Thomas Gais| ${ }^{1+}$
}

\begin{abstract}
Background: Ehlers-Danlos Syndrome (EDS) comprises a heterogeneous group of diseases characterized by joint hypermobility, connective tissue friability, and vascular fragility. Reliable prognostic factors predicting vascular disease progression (e.g. arterial aneurysms, dissections, and ruptures) in EDS patients are still missing. Recently, applanation tonometry derived augmentation index (Alx), an indirect marker of arterial stiffness, has shown to be positively associated with progression of aortic disease in Marfan syndrome. In this study, we assessed aortic Alx in patients with EDS and matched healthy controls.

Methods: We performed noninvasive applanation tonometry in 61 adults with EDS (43 women and 18 men aged $39.3 \pm$ 14.6 years) and 61 age-, gender-, height-, and weight-matched healthy controls. Radial artery pulse waveforms were recorded and analyzed using the SphygmoCor System (AtCor Medical, Sydney, NSW, Australia). Calculated Alx was adjusted to a heart rate of $75 / \mathrm{min}$. Groups were compared and association between Alx and EDS was determined by univariate and multivariate regression analysis.
\end{abstract}

Results: EDS patients were categorized in classical type EDS (34\%), hypermobile type EDS (43\%), vascular type EDS (5\%), or remained unassignable (18\%) due to overlapping features. EDS patients showed a significantly increased aortic Alx compared to healthy controls $(22.8 \% \pm 10.1$ vs $14.8 \% \pm 14.0, p<0.001)$. EDS showed a positive association with Alx; independent of age, sex, height, blood pressure, medication, and pack years of smoking.

Conclusions: Patients with EDS showed elevated Alx, indicating increased arterial stiffness when compared to healthy controls. Further investigations are needed in order to assess the prognostic value of increased Alx for cardiovascular outcomes in patients with EDS.

Keywords: Ehlers-Danlos syndrome, Arterial stiffness, Augmentation index, Cardiovascular risk

\section{Background}

Ehlers-Danlos Syndrome (EDS) represents a heterogeneous group of heritable connective tissue disorders characterized by joint hypermobility, connective tissue friability, as well as skin and vascular fragility. The combined prevalence of all

\footnotetext{
*Correspondence: malcolm.kohler@usz.ch

${ }^{\dagger}$ Malcolm Kohler and Thomas Gaisl contributed equally to this work.

'Department of Pulmonology, University Hospital Zurich, Rämistrasse 100, 8091 Zurich, Switzerland

${ }^{4}$ Centre for Interdisciplinary Sleep Research, University of Zurich, Zurich, Switzerland

Full list of author information is available at the end of the article
}

EDS subtypes appears to be nearly 1 to 5000 individuals world- wide [1]. The current international classification of EDS distinguishes 13 clinical subtypes, for which molecular mutations have been identified in 19 different genes [2].

Vascular fragility with easy bruising is common in all patients with EDS, but its severity varies between EDS subgroups [3]. An increased bleeding tendency including menometrorrhagia, gum bleeding, and peri-operative hemorrhage has been described in many EDS-patients of varying EDS subtypes [3]. Spontaneous aneurysms, dissections and ruptures of medium to large sized arteries,

(c) The Author(s). 2020 Open Access This article is licensed under a Creative Commons Attribution 4.0 International License, which permits use, sharing, adaptation, distribution and reproduction in any medium or format, as long as you give appropriate credit to the original author(s) and the source, provide a link to the Creative Commons licence, and indicate if changes were made. The images or other third party material in this article are included in the article's Creative Commons licence, unless indicated otherwise in a credit line to the material. If material is not included in the article's Creative Commons licence and your intended use is not permitted by statutory regulation or exceeds the permitted use, you will need to obtain permission directly from the copyright holder. To view a copy of this licence, visit http://creativecommons.org/licenses/by/4.0/ The Creative Commons Public Domain Dedication waiver (http://creativecommons.org/publicdomain/zero/1.0/) applies to the data made available in this article, unless otherwise stated in a credit line to the data. 
caused by defects in type III collagen, are a clinical hallmark of the vascular type of EDS (vEDS). These lifethreatening complications result in a reduced life span with a median age of approximately 51 years [4]. Major vascular events have also been described in EDS subtypes with other molecular defects, including defects of collagen I and V or molecules involved in collagen folding (FKBP22), processing (ADAMTS-2) or modification (LH1) [3].

Recent advances in surgical and endovascular management of progressive arterial disease in EDS patients have been associated with good clinical outcomes [5-8]. Nevertheless, due to the difficult handling of fragile tissue and vessels during the operation, a sufficient riskbenefit assessment becomes crucial. Given that spontaneous arterial rupture can also occur in non-dilated arteries, prognostic factors for identification of vascular highrisk patients are indispensable, yet undetermined to date [9].

Arterial tonometry derived augmentation index (AIx) is measured by pulse wave analysis, and is an indirect surrogate measure of arterial stiffness [10]. It has been shown to be an independent predictor of mortality and cardiovascular events in patients with hypertensive, cardiovascular and renal disease [11]. Furthermore, recent findings suggest that the AIx is elevated in patients with Marfan syndrome and correlates with progression of aortic disease [12, 13]. Therefore, in a first step, the AIx of EDS patients was compared to age-, gender-, weight-, and height-matched healthy controls and possible predicting factors were assessed.

\section{Methods}

\section{Study design and participants}

This study was part of a recently published prospective parallel-cohort study, which our group conducted in order to assess the prevalence of obstructive sleep apnoea in patients with EDS [14]. For this purpose, 100 adult patients with EDS were one-to-one matched to 100 healthy adult controls according to sex, age, weight and height. Study procedures included structured interviews (including short-form 36 ), level-3 respiratory polygraphy and arterial tonometry.

Between April and December 2015, EDS patients have been recruited from three different sources: University Children's Hospital Zurich EDS database, University Hospital Zurich EDS database, and an international network based on EDS associations. EDS diagnosis and categorization followed the Villefranche diagnostic criteria [15]. Hypermobility was assessed according to the Beighton score [16]. EDS diagnosis was confirmed either by 1) gene analysis, 2) pathological electron microscope study findings or biochemical analysis of collagen in cultivated fibroblasts suggestive for specific EDS subtypes or 3) increased ratio of deoxypyridinoline to pyridioline crosslinks in biochemical urine analysis for kyphoscoliotic EDS (kEDS: formerly EDS VIA) [17-19]. Healthy control subjects were recruited from the local population in Zurich to specifically match (one-to-one matching) the patients with EDS in terms of sex, age ( \pm 3 years), height $( \pm 20 \mathrm{~cm})$ and weight $( \pm 15 \mathrm{~kg})$. If subjects were aged 18 years or above, physically and intellectually capable to adhere to the study protocol, and were not pregnant, we considered them eligible. 61 patients with EDS agreed to the applanation tonometry at the study site in Zurich and thus were included in the study. Accordingly, 61 matched healthy controls were also investigated and included in this study. All participants provided written informed consent to participate in the study. All procedures were reviewed and approved by the Cantonal Ethics Committee Zurich (registration number KEK-ZH2015-0144) and conformed to the Declaration of Helsinki.

\section{Measurements \\ Pulse wave analysis}

Before pulse wave analysis, subjects had to rest ten minutes in supine position. Subsequently, radial artery pulse waveforms were recorded using the SphygmoCor System (AtCor Medical, Sydney, NSW, Australia). Approximately ten radial pulse waves were measured and a corresponding central aortic pressure waveform was generated using a validated mathematical transfer function [20]. The inflection point of the aortic pressure waveform corresponds to the onset of the reflected wave returning from peripheral arteries and divides the aortic pressure wave into an early and late systolic peak. This inflection point can be determined with an algorithm. The AIx quantifies the augmentation of central aortic pressure, hence representing a measure of peripheral arterial wave reflection. AIx can be calculated as the difference between the second (P2) and the first systolic peak pressure (P1) and is expressed as percentage of central pulse pressure (PP):

$$
\operatorname{AIx}(\%)=[(\mathrm{P} 2-\mathrm{P} 1) / \mathrm{PP}] \times 100 .
$$

Since AIx is influenced by heart rate [21, 22], the index is adjusted to a heart rate of $75 \mathrm{bpm}$. SphygmoCor Px software adjusts the AIx at an inverse rate of $4.8 \%$ for each $10 \mathrm{bpm}$ increment. To ensure a high measurement quality, only measurements with an operator index of 80 and above were accepted. The measurements were conducted by two trained, unblinded researchers.

\section{Data analysis and statistics}

All data are presented as mean \pm standard deviation (SD) or median (quartiles) unless otherwise stated. Groups 
were compared by independent $\mathrm{t}$-test, Wilcoxon rank sum test or ANOVA. Univariate regression analysis was used to investigate association between AIx and EDS as well as possible and known (prespecified) predictors for AIx such as age, sex, height, weight, BMI, blood pressure (BP), smoking status, and use of medication. To further investigate the independent association between AIx and EDS, multivariate analysis was performed including all variables showing $p$-value $<0,1$ in univariate regression analysis. We assessed eight possible clinical predictors with multiple regression analysis. Using a probability level of 0.05 the observed $R^{2}$ of 0.6 in the final model led to a statistical power of $100 \%$ [23, 24]. Residual analysis of the model was performed to check the regression assumption. A two-sided $p$-value of $<0,05$ was considered statistically significant.

\section{Results}

\section{Study participants and baseline characteristics}

A total of 65 EDS patients underwent pulse wave analysis. Due to insufficient measurement quality, four subjects had to be excluded. Subsequently, 61 healthy controls were matched. A total of 122 subjects entered the final analysis of pulse wave analysis measurement (Fig. 1). EDS Patients were categorized in classical type EDS (34\%), hypermobile type EDS (43\%), vascular type EDS (5\%) or remained unassignable (18\%) due to overlapping features although Villefranche inclusion criteria were fulfilled. AIx measurements took place after mean (SD) $10 \pm 13.1$ years after the initial EDS diagnosis. The mean (SD) age in the EDS cohort and the healthy controls was $39.3 \pm 14.6$ years and $35.6 \pm 11.4$ years, respectively. Diastolic BP $(80.6 \pm 10.8 \mathrm{mmHg}$ vs $76.1 \pm 11.8$ $\mathrm{mmHg}$ ) and the number of patients using antihypertensive drugs $(16 \%$ vs $2 \%)$ or NSAIDs $(21 \%$ vs $3 \%)$ was significantly higher in the EDS cohort. The most important class of antihypertensive drugs in EDS patients was ACE inhibitor/ATII receptor blocker (7 out of 10 patients), while one patient of the control group used a betablocker. The detailed patients' characteristics are shown in Tables 1 and 2.

\section{Pulse wave analysis}

EDS patients showed a significantly increased aortic AIx compared to healthy controls $(22.8 \pm 10.1 \%$ vs $14.8 \pm$ $14.0 \%, p<0.001)$ as shown in Fig. 2. The primary wave pressure (P1 height) showed no statistical difference (median (quartiles) $20(16 / 23) \mathrm{mmHg}$ vs $20(17 / 24)$ $\mathrm{mmHg}$ ). While the time to the first aortic pressure peak (T1) was comparable, the time to the second aortic pressure peak (T2) and the ejection duration (ED) was significantly shorter in the EDS cohort. EDS patients had a significantly higher resting heart rate during the pulse wave analysis. Patients suffering vascular type EDS showed the highest AIx (mean (SD) $31.2 \pm 14.1 \%$ ), even though there was no statistical difference between the assessed EDS subtypes. Detailed information about the results of pulse wave analysis are shown in Table 3.

\section{Predictors of aortic Alx}

AIx was positively associated with age, diastolic BP, pack years of smoking, and use of antihypertensive drugs. Male sex, weight and height were negatively associated with AIx in univariate regression analysis (Table 4). Table 5 presents the independent predictors of AIx analyzed by a multiple regression model. EDS showed a significant, positive, and independent association with AIx (Coef. (95\% CI) of 3.85 (0.41 to 7.29), $p=0.029$ ). While age, diastolic BP and pack years of smoking were independently associated with AIx, the use of medication showed no independent association in the multiple regression analysis. Height and male sex showed a negative, independent association with AIx. Due to strong correlation between height and weight $(\mathrm{r}=0.70, p<$ 0.001 ), weight was removed from the final model.

\section{Discussion}

This study investigated the applanation tonometry derived augmentation index (AIx) in a well characterized cohort of EDS patients. EDS patients showed a significantly, independently increased AIx compared to matched healthy controls, suggesting increased arterial stiffness in EDS patients despite the known influencing factors such as age, sex, BP and smoking history. Although vascular EDS patients showed the highest AIx $(31.2 \pm 14.1 \%)$, no significant overall differences of the AIx could be observed between the different types of EDS.

The aortic AIx is used as an indirect index of vascular stiffness derived from aortic pressure waveform analysis $[25,26]$. It represents the ratio of the ejection pressure from the heart and the reflection pressure from the arterial system. In this study, the primary wave pressure (P1), which represents the primary left ventricular ejection pressure, showed no difference between EDS patients and healthy controls, leading to the conclusion, that the observed difference in AIx results from the arterial reflection wave. These findings suggest that the increased AIx might represent increased arterial stiffness in EDS patients. This hypothesis is supported by the fact that the time of the second aortic peak (T2) was significantly shorter in the EDS cohort, while the time for the first peak (T1) was comparable. The finding of an increased AIx in EDS patients cannot be compared to other studies yet due to missing literature on this topic. However, since the AIx of our healthy controls (14.8 \pm $14.0 \%)$ are comparable to expected reference values obtained from larger unselected population-based studies 


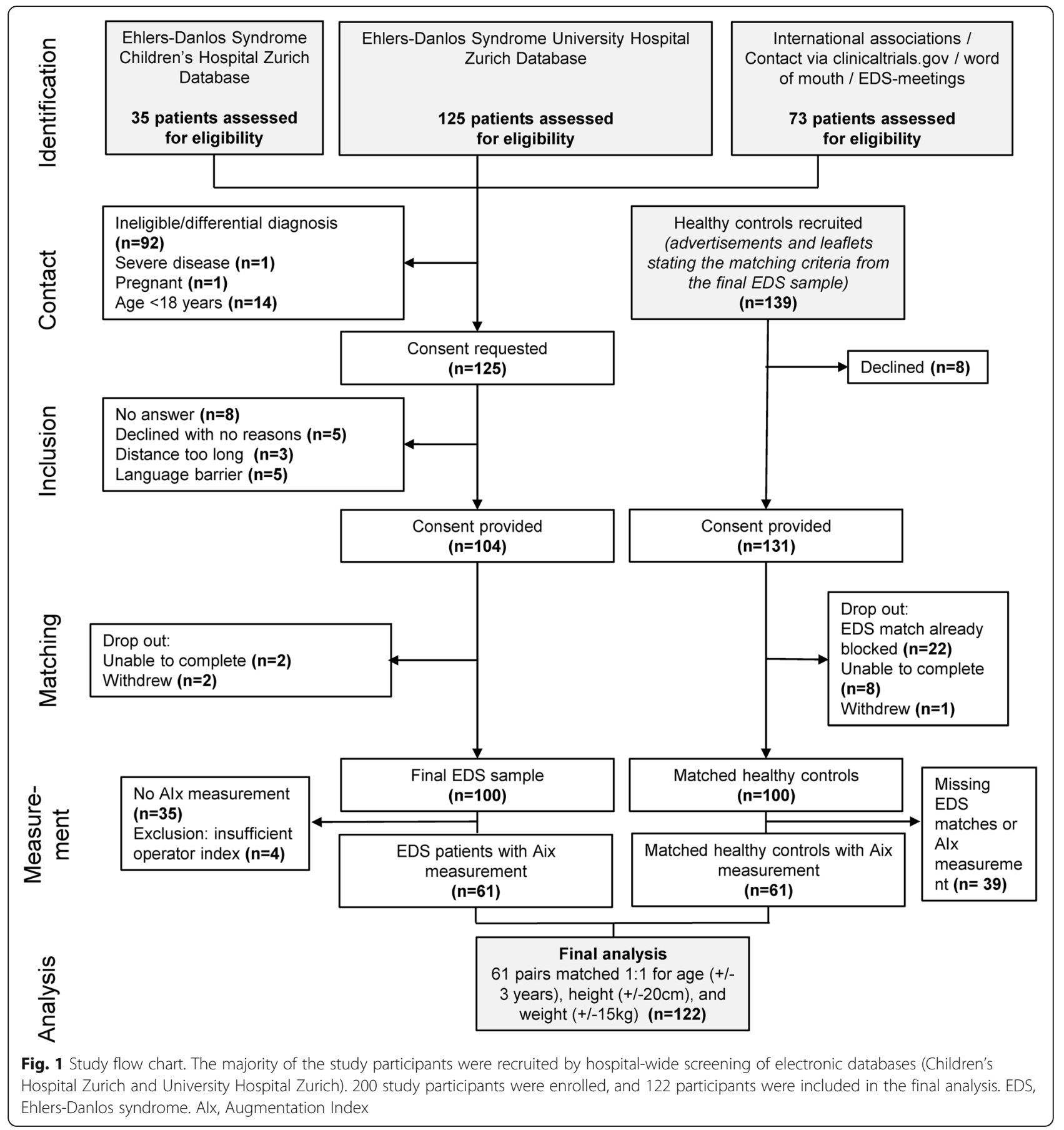

the findings in EDS seems to be plausible [27]. Furthermore, AIx was positively correlated to female gender, age, diastolic BP, and pack years of smoking, and was also negatively correlated to height and weight as reported in previous studies [27-30].

Literature about arterial stiffness and cardiovascular risk in EDS patients is rare and the existing results are incongruent due to inhomogeneous study populations and different methods used to determine arterial stiffness [31-35]. Population inhomogeneity is mainly based on the fact that EDS is an umbrella term for clinically diverse connective tissue disorders based on different genetic defects [36].

Our results contradict in particular a recently published study by Miller et al., reporting increased arterial elasticity in patients with EDS measured by pulse wave velocity (PWV) [35]. Nevertheless, this study only retrospectively analyzed a subset of EDS patients from the 
Table 1 Baseline characteristics of the 122 one-to-one matched study participants

\begin{tabular}{|c|c|c|c|}
\hline & EDS cohort $(n=61)$ & Healthy control cohort $(n=61)$ & $\boldsymbol{p}$-value \\
\hline $\operatorname{Sex}(f / m)$ & $43 / 18$ & $43 / 18$ & - \\
\hline Caucasian, \% & 100 & 100 & - \\
\hline Age, years & $39.3 \pm 14.6$ & $35.6 \pm 11.4$ & 0.13 \\
\hline Height, cm & $168.5(161.0 / 174.5)$ & $169.0(162.5 / 176.5)$ & 0.47 \\
\hline Weight, cm & $65.0(54.0 / 76.0)$ & $65.0(58.0 / 75.5)$ & 0.73 \\
\hline $\mathrm{BMI}, \mathrm{kg} / \mathrm{m}^{2}$ & $22.7(20.4 / 25.9)$ & $22.9(20.8 / 24.7)$ & 0.96 \\
\hline BSA, $m^{2}$ & $1.3(1.1 / 1.5)$ & $1.3(1.2 / 1.5)$ & 0.81 \\
\hline Neck, cm & $33(31 / 37)$ & $33(32 / 37)$ & 0.70 \\
\hline Waist, $\mathrm{cm}$ & $73(67 / 85)$ & $76(69.0 / 81.0)$ & 0.87 \\
\hline Blood pressure systolic (office), mmHg & $117.4 \pm 14.2$ & $112.8 \pm 12.8$ & 0.07 \\
\hline Blood pressure diastolic (office), $\mathrm{mmHg}$ & $80.6 \pm 10.8$ & $76.1 \pm 11.8$ & 0.03 \\
\hline Pulse, $\min ^{-1}$ & $76.7(67 / 84.7)$ & $69.0(64.0 / 76.7)$ & 0.025 \\
\hline Alcohol units per week, units & $0(0 / 1)$ & $0(0 / 2)$ & 0.74 \\
\hline Current Smoker, n (\%) & $15(25 \%)$ & $9(15 \%)$ & 0.20 \\
\hline Diabetes, n (\%) & $3(4.9 \%)$ & $0(0 \%)$ & 0.08 \\
\hline Arterial hypertension, n (\%) & $10(16 \%)$ & $1(2 \%)$ & 0.004 \\
\hline Pack years of smoking, $\mathrm{n}$ & $0(0 / 3)$ & $0(0 / 1)$ & 0.11 \\
\hline Antihypertensive drugs, n (\%) & $10(16 \%)$ & $1(2 \%)$ & 0.004 \\
\hline NSAIDs, n (\%) & $13(21 \%)$ & $2(3 \%)$ & 0.002 \\
\hline Lipid lowering drugs, n (\%) & 0 & 0 & - \\
\hline Antiplatelet drugs, n (\%) & $1(1.64 \%)$ & 0 & 0.32 \\
\hline Antidiabetic drugs, n (\%) & 0 & 0 & - \\
\hline
\end{tabular}

EDS Ehlers-Danlos Syndrome; BMI Body-Mass-Index; BSA body surface area; NSAID non-steroidal anti-inflammatory drugs

Clinical and Molecular Manifestations of HDCT study who had both orthostatic BP recordings and PWV measurements [37]. There might be a selection bias, because the authors focused especially on the connection between orthostatic intolerance (OI) and EDS patients. The comparison of these results with our study has to be done with caution, as only few information on study population is available and the EDS patients were not matched to a healthy control group. Nevertheless, we have to point out that AIx is a measure of pressure wave reflection, while PWV is the most commonly and universally acceptable measure of arterial stiffness. The assessment of central/aortic pressures, PWR and AIx in this specific population compared to healthy controls are of great interest and should be the focus of future research.
Vascular complications in patients with EDS are historically attributed to impaired synthesis and processing of diverse collagen types, leading to fragility of blood vessel walls and perivascular connective tissue, thus a decreased arterial stiffness would be suspected. However, molecular pathomechanisms underlying development of arterial aneurysms, dissections, rupture and bleeding are poorly understood [3]. It is to mention that arterial stiffness is not only determined by the arterial wall's composition of elastin and collagen. For example, smooth muscle cells behave as a stiff material linking fibrous component and contribute to arterial stiffness especially when contracted [38-40]. Furthermore, animal studies suggest that effective arterial stiffness results from complex interactions between smooth muscle cells and extracellular matrix. For instance, increased fibronectin,

Table 2 Aortic Augmentation Index @HR 75 in different EDS subtypes

\begin{tabular}{|c|c|c|c|c|c|}
\hline EDS type & Classical type & Hypermobile type & Vascular type & Not assignable ${ }^{a}$ & $\overline{p \text {-value }}$ \\
\hline $\bar{N}$ & $21(34 \%)$ & $26(43 \%)$ & $3(5 \%)$ & $11(18 \%)$ & - \\
\hline Beighton score & $5.7 \pm 2.5$ & $5.4 \pm 2.5$ & $2.3 \pm 1.5$ & $5.5 \pm 2.5$ & 0.199 \\
\hline Aortic Augmentation Index @HR 75, \% & $22 \pm 11$ & $22 \pm 11$ & $32 \pm 10$ & $25 \pm 11$ & 0.451 \\
\hline
\end{tabular}

${ }^{a}$ Not clearly attributable due to overlapping features, although Villefranche inclusion criteria are fulfilled. Patients fulfilling diagnostic criteria for more than one EDS subtype were labeled "not assignable" for this study. EDS Ehlers-Danlos Syndrome; HR heart rate 


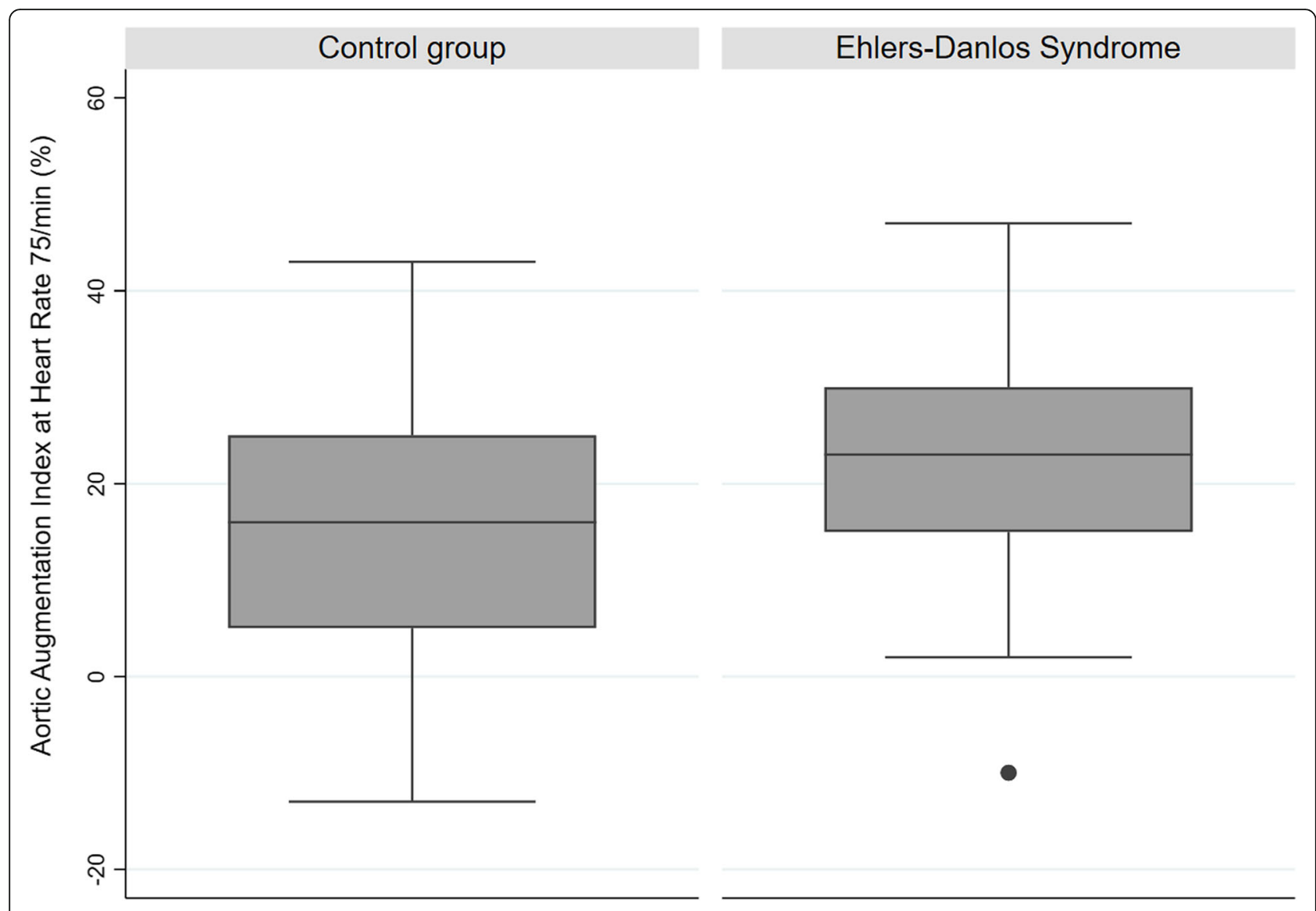

Fig. 2 Box plots for aortic augmentation index adjusted to heart rate of 75/min by groups

an extracellular protein, is associated with a cell dedifferentiation process leading to increased production of extracellular matrix proteins by smooth muscle cells [41]. Stewart et al. [42] found that the aortic AIx and carotid-femoral pulse wave velocity increases after the application of a nitric oxide synthase inhibitor, thus pointing out the importance of basal nitric oxide on functional regulation of central arteries in humans. $\mathrm{Ni}$ tric oxide synthesis could be altered in EDS patients given the recent finding that markers of endothelial dysfunction such as VCAM-1, ICAM-1 and MCP-1 are increased in vEDS patients [43].

Our EDS patients showed increased resting heart rate and $\mathrm{BP}$ compared to healthy controls. Increased resting

Table 3 Pulse wave analysis in both cohorts

\begin{tabular}{llll}
\hline & EDS cohort $(n=61)$ & Healthy control cohort $(n=61)$ & $p$-value \\
\hline Aortic Alx (AP/PP) @HR 75, \% & $22.8 \pm 10.1$ & $14.8 \pm 14.0$ & $<0.001$ \\
P1 height, mmHg & $20(16 / 23)$ & $20(17 / 24)$ & 0.438 \\
Peripheral T1, ms & $113(104 / 122)$ & $109(104 / 119)$ & 0.288 \\
Peripheral T2, ms & $200(191 / 212)$ & $209(202 / 221)$ & 0.002 \\
Peripheral Alx, \% & $80.4 \pm 18.2$ & $72.5 \pm 17.2$ & 0.017 \\
End systolic pressure, mmHg & $102(92 / 109)$ & $97(91 / 105)$ & $302(288 / 316)$ \\
Ejection duration, ms & $296(276 / 309)$ & $67(63 / 72)$ & 0.103 \\
Heart rate, min ${ }^{-1}$ & $76(67 / 83)$ & $96(90 / 102)$ & 0.025 \\
Mean pressure systolic, mmHg & $99(91 / 107)$ & $85(79 / 91)$ & 0.001 \\
Mean pressure diastolic, mmHg & $89(82 / 96)$ & 0.069 \\
\hline
\end{tabular}

Alx Augmentation index; EDS Ehlers-Danlos Syndrome; HR heart rate 
Table 4 Univariate regression analysis of possible predictors for aortic Alx (AP/PP) normalized for a heart rate of 75/min in all study subjects $(n=122)$

\begin{tabular}{|c|c|c|c|}
\hline Variable & Coefficient & 95\% Confidence Interval & $p$-value \\
\hline Age, years & 0.43 & 0.27 to 0.59 & $<0.001$ \\
\hline Male sex, (yes/no) & -13.36 & -17.96 to -8.76 & $<0.001$ \\
\hline Height, $\mathrm{cm}$ & -0.61 & -0.80 to -0.42 & $<0.001$ \\
\hline Weight, kg & -0.21 & -0.36 to -0.06 & 0.007 \\
\hline $\mathrm{BMI}, \mathrm{kg} / \mathrm{m}^{2}$ & 0.19 & -0.40 to 0.78 & 0.532 \\
\hline Ehlers-Danlos Syndrome, (yes/no) & 8.10 & 3.59 to 12.60 & 0.001 \\
\hline Mean systolic blood pressure, $\mathrm{mmHg}$ & 0.124 & -0.05 to 0.30 & 0.168 \\
\hline Mean diastolic blood pressure, $\mathrm{mmHg}$ & 0.42 & 0.22 to 0.61 & $<0.001$ \\
\hline Smoking, (yes/no) & 2.78 & -3.18 to 8.79 & 0.357 \\
\hline Pack years of smoking, $n$ & 0.41 & 0.12 to 0.69 & 0.006 \\
\hline Antihypertensive Drugs, (yes/no) & 8.67 & 0.55 to 16.79 & 0.037 \\
\hline Antiplatelet Drugs, (yes/no) & -5.88 & -32.13 to 20.37 & 0.658 \\
\hline NSAID, (yes/no) & 7.03 & -0.07 to 14.19 & 0.052 \\
\hline
\end{tabular}

Alx Augmentation index; BMI Body-Mass-Index; NSAID non-steroidal anti-inflammatory drugs

sympathetic activity has already been described as part of autonomic dysregulation in EDS patients [44]. The connection between elevated BP, increased arterial stiffness and vascular disease has been extensively reviewed in the general literature about cardiovascular pathology. Chronic elevated BP leads to decreased vascular distensability that, in turn, increases pulsatile shear stress and pressure leading to endothelial dysfunction and vascular disease $[45,46]$. Increased arterial wall stress in EDS patients compared to healthy controls has been reported by Boutouyrie et al. [47] using high-resolution echotracking systems.

Shingu et al. [48] found an elevated carotid AIx in patients with aortic aneurysm and dissection, which the authors attributed to increased left ventricular afterload. Whether an increased prevalence of aortic aneurysms and dissections could be a reason for the increased AIx in our EDS cohort remains unknown because study subjects did not undergo vasculopathy evaluation. Depending on EDS subtypes, EDS patients suffer joint pain, joint dislocation, muscle cramps and fatigue leading to significantly reduced physical activity [49]. There are several studies suggesting a link between decreased physical activity and increased arterial stiffness [50, 51]. Even when only considering the number of reported joint luxation in our EDS cohort (22\% of all EDS patients), reduced daily activity as a cause for increase arterial stiffness should be considered. In this study, EDS patients used more NSAIDs and antihypertensive medication compared to healthy controls. The influence of several medications, including antihypertensive and antiinflammatory drugs on arterial stiffness has been described in literature [41], but no independent pharmacological influence on the AIx was observed in our study. Furthermore, it is to mention that no EDS patient was treated with Celiprolol, a cardioselective $\beta$-blocker that has recently been shown to increase stiffness of the common carotid artery in vEDS patients [52].

Since medical and interventional management advances lead to improved survival and quality of life in

Table 5 Multivariate linear regression analysis of possible predictors for aortic Alx (AP/PP) normalized for a heart rate of $75 / \mathrm{min}$ in all study subjects $(n=122)$

\begin{tabular}{llll}
\hline Variable & Coefficient & 95\% Confidence Interval & $\boldsymbol{p}$-value \\
\hline Ehlers-Danlos Syndrome, (yes/no) & 3.85 & 0.41 to 7.29 & $\mathbf{0 . 0 2 9}$ \\
Height, cm & -0.43 & -0.64 to -0.23 & $\mathbf{<}$ \\
Male sex, (yes/no) & -8.00 & -12.48 to -3.52 & 0.001 \\
Age, years & 0.32 & 0.18 to 0.46 & $\mathbf{<}$ \\
Pack years of smoking, $\mathrm{0.001}$ & 0.26 & 0.05 to 0.47 & $\mathbf{0 . 0 1 5}$ \\
Mean diastolic blood pressure, mmHg & 0.16 & 0.01 to 0.31 & $\mathbf{0 . 0 4 2}$ \\
Antihypertensive drugs, (yes/no) & 3.75 & -1.82 to 9.33 & 0.185 \\
NSAID, (yes/no) & 1.00 & -3.99 to 5.99 & 0.692 \\
\hline
\end{tabular}

Alx Augmentation index; NSAID non-steroidal anti-inflammatory drugs 
EDS patients, the role of early identification of vascular high-risk patients gains importance. To date, little is known about prognostic factors that could predict the chance of developing fatal cardiovascular events in patients with EDS. Pepin et al. [4] recently showed that the natural course of vEDS varies with gender and type of mutation in COL3A1. This group showed a 5-year survival difference between males and females which was primarily based on a higher death rate before age of 20 due to vascular rupture. Vascular inflammation marker has been shown to be significantly elevated in vascular EDS patients compared to matched controls [53]. However, their potential to predict vascular complications in EDS patients are still subject of ongoing investigation [43].

Increased applanation tonometry derived AIx has been reported in patients with Marfan syndrom [13], a genetic connective tissue disorder due to mutation in the fibrillin 1 gene [54]. These patients also suffer from fatal vascular events like aortic dissection and rupture [55]. Mortensen et al. [13] conducted a longitudinal observational study to follow-up cardiovascular disease progression in 50 adult patients with Marfan syndrome for almost 2 years. Beside baseline aortic root diameter, only aortic AIx showed an independent association to aortic disease progression. Furthermore, Kaplan-Meier curve analysis presented a significantly lower rate of aortic root disease in patients with lower AIx [12]. EDS and Marfan syndrome are multisystemic disorders that primarily affect the soft connective tissues. Even if these disorders differ in genetic and molecular pathogenesis, there are at least some clinical overlaps [36] suggesting that the increased AIx might predict vascular disease progression in EDS patients as reported in Marfan syndrome patients. In addition, the fact that the other "non-vascular" EDS subtypes showed increased AIx as well, could point out an increased risk for cardiovascular events beside the vEDS-typical vascular complications. However, data about the general cardiovascular risk in EDS patients compared to the general population are lacking.

There are some limitations to our study. The patient numbers of EDS subtypes, especially of vEDS, were relatively small to allow statistical comparison of different AIx values between different subtypes. Nonetheless, related to EDS incidence, the number of acquired patients was considerable. Arterial stiffness was not the primary outcome of this study, hence no specific power calculation for pulse wave analysis measurement were done. However, the AIx difference measured in EDS patients and healthy controls was considerably. In addition, our study design did not allow a longitudinal follow-up of cardiovascular events in EDS patients. Further longitudinal studies assessing AIx and cardiovascular events in EDS patients would be needed to show the clinical relevance of increased AIx as a prognostic factor for cardiovascular risk in these patients. Nevertheless, since vEDS patients harbor the highest risk for fatal vascular events and this subgroup presented the highest AIx in our study, AIx already indicate potential as a possible predictor for vascular high-risk patients.

\section{Conclusion}

This study showed increased applanation tonometry derived AIx in patients with EDS suggesting elevated arterial stiffness compared to healthy controls. Additional investigations have to assess the predictive value of increased arterial stiffness regarding general cardiovascular risk in patients with EDS. Furthermore, prospective observational studies are needed in order to evaluate whether AIx might provide similar prediction of aortic disease progression as it was shown in patients with Marfan syndrome.

\section{Abbreviations}

Alx: Augmentation index; AP: Augmentation pressure; BMl: Body mass index; BP: Blood pressure; BSA: Body surface area; Coef.: Coefficient;

COL1A1: Collagen type III alpha 1 chain; ED: End of ejection; EDS: Ehlers-

Danlos syndrome; HR: Heart rate; ICAM-1: Intercellular adhesion molecule 1;

kEDS: Kyphoscoliotic Ehlers-Danlos syndrome; MCP-1: Monocyte

chemoattractant protein 1; Min: Minute; NSAID: Non-steroidal anti-

inflammatory drug; PP: Pulse pressure; SD: Standard deviation; VCAM-

1: Vascular cell adhesion molecule 1; vEDS: Vascular type of Ehlers-Danlos syndrome

\section{Acknowledgements}

We thank the participants, organizations, and relatives who gave so much for this study and often travelled long distances to participate in this study. Specifically: Dirk Hochtritt, Rea Spörri, Jasmin Polsini (Ehlers-Danlos Netz Schweiz); Juergen Grunert, Friederike Müller, Markus Irene, Wibke

Jungermann (Deutsche Ehlers-Danlos-Initiative e.V.); Barbara Kleffmann (Ehlers-Danlos-Selbsthilfe e.V.) for administrative support; Stefanie Armbruster who supported the recruitment process; Matthias Baumann (Medical University of Innsbruck, Austria) for the help during the recruitment process.

\section{Authors' contributions}

TG, CG, MR, and MK conceived, designed, and analyzed the overall study. TG and MK designed and coordinated data collection. TG, MR, FB and ST performed the statistical analysis. TG, CS, ST, FB and NS assessed study outcomes. TG and MK undertook the administration of the study. TG and MK applied for funding for this study. TG and NS oversaw the study assessments. All authors oversaw, contributed and approved the final manuscript.

\section{Funding}

The research was supported by grants from "Lunge Zürich" and "Lungenliga Schweiz". Beside the financial support, both organizations had no role in any study process

\section{Availability of data and materials}

The datasets used and/or analysed during the current study are available from the corresponding author on reasonable request.

\section{Ethics approval and consent to participate}

All participants provided written informed consent to participate in the study. If patients were $<18$ years old, written parental consent has been obtained. All procedures were reviewed and approved by the Cantonal Ethics Committee Zurich (registration number KEK-ZH- 2015-0144) and conformed to the Declaration of Helsinki.

Consent for publication

Not applicable. 


\section{Competing interests}

None.

\section{Author details}

'Department of Pulmonology, University Hospital Zurich, Rämistrasse 100, 8091 Zurich, Switzerland. ${ }^{2}$ Clinical and Interventional Angiology, University Hospital Zurich, Zurich, Switzerland. 'Division of Metabolism and Children's Research Center University Children's Hospital Zurich, Zurich, Switzerland ${ }^{4}$ Centre for Interdisciplinary Sleep Research, University of Zurich, Zurich, Switzerland

Received: 5 November 2019 Accepted: 25 August 2020 Published online: 15 September 2020

\section{References}

1. Genetic Home Reference, https://ghr.nlm.nih.gov/condition/ehlers-danlossyndrome\#statistics, accessed on 04 August 2020.

2. Malfait F, Francomano C, Byers P, Belmont J, Berglund B, Black J, et al. The 2017 international classification of the Ehlers-Danlos syndromes. Am J Med Genet C: Semin Med Genet. 2017;175(1):8-26.

3. Malfait F. Vascular aspects of the Ehlers-Danlos Syndromes. Matrix Biol. 2018; 71-72:380-95.

4. Pepin MG, Schwarze U, Rice KM, Liu M, Leistritz D, Byers PH. Survival is affected by mutation type and molecular mechanism in vascular EhlersDanlos syndrome (EDS type IV). Gene Med. 2014;16(12):881-8.

5. Brooke BS, Arnaoutakis G, McDonnell NB, Black JH 3rd. Contemporary management of vascular complications associated with Ehlers-Danlos syndrome. J Vasc Surg. 2010;51(1):131-8 discussion 8-9.

6. Geisbusch P, Kotelis D, von Tengg-Kobligk H, Hyhlik-Durr A, Allenberg JR, Bockler D. Thoracic aortic endografting in patients with connective tissue diseases. J Endovasc Ther. 2008:15(2):144-9.

7. Mortani Barbosa EJ, Jr., Pyeritz RE, Litt H, Desjardins B. Vascular Ehlers-Danlos syndrome presenting as rapidly progressive multiple arterial aneurysms and dissections. Am J Med Gene A. 2011;155a(12):3090-4

8. Shalhub S, Black JH 3rd, Cecchi AC, Xu Z, Griswold BF, Safi HJ, et al. Molecular diagnosis in vascular Ehlers-Danlos syndrome predicts pattern of arterial involvement and outcomes. J Vasc Surg. 2014;60(1):160-9.

9. Lum YW, Brooke BS, Black JH 3rd. Contemporary management of vascular Ehlers-Danlos syndrome. Curr Opin Cardiol. 2011;26(6):494-501.

10. Nürnberger J, Keflioglu-Scheiber A, Opazo Saez AM, Wenzel RR, Philipp T, Schäfers RF. Augmentation index is associated with cardiovascular risk. J Hypertens. 2002;20(12):2407-14.

11. Laurent S, Cockcroft J, Van Bortel L, Boutouyrie P, Giannattasio C, Hayoz D, et al. Expert consensus document on arterial stiffness: methodological issues and clinical applications. Eur Heart J. 2006;27(21):2588-605.

12. Mortensen K, Aydin MA, Rybczynski M, Baulmann J, Schahidi NA, Kean G, et al. Augmentation index relates to progression of aortic disease in adults with Marfan syndrome. Am J Hypertens. 2009;22(9):971-9.

13. Payne RA, Hilling-Smith RC, Webb DJ, Maxwell SR, Denvir MA. Augmentation index assessed by applanation tonometry is elevated in Marfan Syndrome. J Cardiothorac Surg. 2007;2:43.

14. Gaisl T, Giunta C, Bratton DJ, Sutherland K, Schlatzer C, Sievi N, et al. Obstructive sleep apnoea and quality of life in Ehlers-Danlos syndrome: a parallel cohort study. Thorax. 2017;72(8):729-35.

15. Steinmann B, Royce PM, Superti-Furga A. The Ehlers-Danlos Syndrome. In: Steinmann B, Royce PM. Connective Tissue and its Heritable Disorders, 2002, p. 431-523.

16. Grahame R, Bird HA, Child A. The revised (Brighton 1998) criteria for the diagnosis of benign joint hypermobility syndrome (BJHS). J Rheumatol. 2000;27(7):1777-9.

17. Giunta C, Randolph A, Al-Gazali LI, Brunner HG, Kraenzlin ME, Steinmann B. Nevo syndrome is allelic to the kyphoscoliotic type of the Ehlers-Danlos syndrome (EDS VIA). Am J Med Gene A. 2005;133a(2):158-64.

18. Pasquali M, Dembure PP, Still MJ, Elsas LJ. Urinary pyridinium cross-links: a noninvasive diagnostic test for Ehlers-Danlos syndrome type VI. N Engl J Med. 1994:331(2):132-3.

19. Steinmann B, Eyre DR, Shao P. Urinary pyridinoline cross-links in EhlersDanlos syndrome type VI. Am J Hum Genet. 1995;57(6):1505-8.

20. Pauca Alfredo L, O'Rourke Michael F, Kon ND. Prospective evaluation of a method for estimating ascending aortic pressure from the radial artery pressure waveform. Hypertension. 2001;38(4):932-7.
21. Wilkinson IB, MacCallum H, Flint L, Cockcroft JR, Newby DE, Webb DJ. The influence of heart rate on augmentation index and central arterial pressure in humans. J Physiol. 2000;525(Pt 1):263-70.

22. Wilkinson IB, Mohammad NH, Tyrrell S, Hall IR, Webb DJ, Paul VE, et al. Heart rate dependency of pulse pressure amplification and arterial stiffness. Am J Hypertens. 2002;15(1 Pt 1):24-30.

23. Cohen J. Applied multiple regression correlation analysis for the behavioral sciences. 3rd ed. Mahwah: Erlbaum; 2003. p. 703.

24. Cohen JW. Statistical power analysis for the behavioral sciences. Second Edition, reprinted 2009 ed. New York: Psychology Press; 1988. XXI, 567 Seiten $\mathrm{p}$.

25. O'Rourke MF, Mancia G. Arterial stiffness. J Hypertens. 1999;17(1):1-4.

26. O'Rourke MF, Staessen JA, Vlachopoulos C, Duprez D, Plante GE. Clinical applications of arterial stiffness; definitions and reference values. Am J Hypertens. 2002:15(5):426-44.

27. Janner JH, Godtfredsen NS, Ladelund S, Vestbo J, Prescott E. Aortic augmentation index: reference values in a large unselected population by means of the SphygmoCor device. Am J Hypertens. 2010;23(2):180-5.

28. Matsui Y, Kario K, Ishikawa J, Eguchi K, Hoshide S, Shimada K. Reproducibility of arterial stiffness indices (pulse wave velocity and augmentation index) simultaneously assessed by automated pulse wave analysis and their associated risk factors in essential hypertensive patients. Hypertens Res. 2004;27(11):851-7.

29. O'Rourke MF, Adji A. An updated clinical primer on large artery mechanics: implications of pulse waveform analysis and arterial tonometry. Curr Opin Cardiol. 2005;20(4):275-81.

30. Rehill N, Beck CR, Yeo KR, Yeo WW. The effect of chronic tobacco smoking on arterial stiffness. Br J Clin Pharmacol. 2006:61(6):767-73.

31. Cheng JL, Au JS, Guzman JC, Morillo CA, MacDonald MJ. Cardiovascular profile in postural orthostatic tachycardia syndrome and Ehlers-Danlos syndrome type III. Clin Auton Res. 2017;27(2):113-6.

32. Merlocco A, Lacro RV, Gauvreau K, Rabideau N, Singh MN, Prakash A. Longitudinal changes in segmental aortic stiffness determined by cardiac magnetic resonance in children and young adults with connective tissue disorders (the Marfan, Loeys-Dietz, and Ehlers-Danlos syndromes, and nonspecific connective tissue disorders). Am J Cardiol. 2017:120(7):1214-9.

33. Mirault T, Pernot M, Frank M, Couade M, Niarra R, Azizi M, et al. Carotid stiffness change over the cardiac cycle by ultrafast ultrasound imaging in healthy volunteers and vascular Ehlers-Danlos syndrome. J Hypertens. 2015; 33(9):1890-6 discussion 6.

34. Sonesson B, Hansen F, Länne T. The mechanical properties of elastic arteries in Ehlers-Danlos syndrome. Eur J Vasc Endovasc Surg. 1997;14(4):258-64.

35. Miller AJ Schubart JR, Sheehan T, Bascom R, Francomano CA. Arterial elasticity in Ehlers-Danlos syndromes. Genes. 2020;11(1):55.

36. Callewaert B, Malfait F, Loeys B, De Paepe A. Ehlers-Danlos syndromes and Marfan syndrome. Best Pract Res Clin Rheumatol. 2008;22(1):165-89.

37. Bascom R, Schubart JR, Mills S, Smith T, Zukley LM, Francomano CA, et al. Heritable disorders of connective tissue: description of a data repository and initial cohort characterization. Am J Med Genet A. 2019:179(4):552-60.

38. Nichols WW ORM. McDonald's blood flow in arteries. 1990.

39. Bank AJ, Kaiser DR, Rajala S, Cheng A. In vivo human brachial artery elastic mechanics: effects of smooth muscle relaxation. Circulation. 1999;100(1):41-7.

40. Bank Alan J, Wang H, Holte James E, Mullen K, Shammas R, Kubo SH. Contribution of collagen, elastin, and smooth muscle to in vivo human brachial Artery Wall stress and elastic modulus. Circulation. 1996:94(12): 3263-70.

41. Boutouyrie $P$, Lacolley $P$, Briet $M$, Regnault $V$, Stanton $A$, Laurent $S$, et al. Pharmacological modulation of arterial stiffness. Drugs. 2011;71(13):1689-701.

42. Stewart AD, Millasseau SC, Kearney MT, Ritter JM, Chowienczyk PJ. Effects of inhibition of basal nitric oxide synthesis on carotid-femoral pulse wave velocity and augmentation index in humans. Hypertension. 2003;42(5):915-8.

43. Milewicz DM, Reid AJ, Cecchi AC. Vascular Ehlers-Danlos syndrome: exploring the role of inflammation in arterial disease. Circ Cardiovasc Genet. 2014:7(1):5-7.

44. De Wandele I, Rombaut L, Leybaert L, Van de Borne P, De Backer T, Malfait $F$, et al. Dysautonomia and its underlying mechanisms in the hypermobility type of Ehlers-Danlos syndrome. Semin Arthritis Rheum. 2014:44(1):93-100

45. Benetos A, Laurent S, Hoeks AP, Boutouyrie PH, Safar ME. Arterial alterations with aging and high blood pressure. A noninvasive study of carotid and femoral arteries. Arterioscler Thromb. 1993;13(1):90-7. 
46. Resnick LM, Militianu D, Cunnings AJ, Pipe JG, Evelhoch JL, Soulen RL. Direct magnetic resonance determination of aortic distensibility in essential hypertension: relation to age, abdominal visceral fat, and in situ intracellular free magnesium. Hypertension. 1997;30(3 Pt 2):654-9.

47. Boutouyrie P, Germain DP, Fiessinger JN, Laloux B, Perdu J, Laurent S. Increased carotid wall stress in vascular Ehlers-Danlos syndrome. Circulation. 2004;109(12):1530-5.

48. Shingu Y, Shiiya N, Ooka T, Tachibana T, Kubota S, Morita S, et al. Augmentation index is elevated in aortic aneurysm and dissection. Ann Thorac Surg. 2009:87(5):1373-7.

49. Rombaut L, Malfait F, Cools A, De Paepe A, Calders P. Musculoskeletal complaints, physical activity and health-related quality of life among patients with the Ehlers-Danlos syndrome hypermobility type. Disabil Rehabil. 2010;32(16):1339-45.

50. Park W, Park H-Y, Lim K, Park J. The role of habitual physical activity on arterial stiffness in elderly individuals: a systematic review and meta-analysis. J Exerc Nutrition Biochem. 2017;21(4):16-21.

51. Sievi NA, Franzen D, Kohler M, Clarenbach CF. Physical inactivity and arterial stiffness in COPD. Int J Chron Obstruct Pulmon Dis. 2015;10:1891-7.

52. Ong K-T, Perdu J, De Backer J, Bozec E, Collignon P, Emmerich J, et al. Effect of celiprolol on prevention of cardiovascular events in vascular EhlersDanlos syndrome: a prospective randomised, open, blinded-endpoints trial. Lancet. 2010;376(9751):1476-84.

53. Morissette R, Schoenhoff F, Xu Z, Shilane DA, Griswold BF, Chen W, et al. Transforming growth factor-beta and inflammation in vascular (type IV) Ehlers-Danlos syndrome. Circ Cardiovasc Genet. 2014;7(1):80-8.

54. Dietz HC, Cutting GR, Pyeritz RE, Maslen CL, Sakai LY, Corson GM, et al. Marfan syndrome caused by a recurrent de novo missense mutation in the fibrillin gene. Nature. 1991;352(6333):337-9.

55. Murdoch JL, Walker BA, Halpern BL, Kuzma JW, McKusick VA. Life expectancy and causes of death in the Marfan syndrome. N Engl I Med. 1972;286(15):804-8.

\section{Publisher's Note}

Springer Nature remains neutral with regard to jurisdictional claims in published maps and institutional affiliations.

Ready to submit your research? Choose BMC and benefit from:

- fast, convenient online submission

- thorough peer review by experienced researchers in your field

- rapid publication on acceptance

- support for research data, including large and complex data types

- gold Open Access which fosters wider collaboration and increased citations

- maximum visibility for your research: over $100 \mathrm{M}$ website views per year

At $\mathrm{BMC}$, research is always in progress.

Learn more biomedcentral.com/submissions 